\title{
Submillimeter Wave Antenna With Slow Wave Feed Line
}

\author{
Zhurbenko, Vitaliy; Krozer, Viktor; Kotiranta, Mikko; Rubæk, Tonny; Durand, Alain; Marchesin, Rodolphe
}

Published in:

2009 SBMO/IEEE MTT-S International Microwave and Optoelectronics Conference (IMOC)

Link to article, DOI:

10.1109/IMOC.2009.5427560

Publication date:

2009

Document Version

Publisher's PDF, also known as Version of record

Link back to DTU Orbit

Citation (APA):

Zhurbenko, V., Krozer, V., Kotiranta, M., Rubæk, T., Durand, A., \& Marchesin, R. (2009). Submillimeter Wave Antenna With Slow Wave Feed Line. In 2009 SBMO/IEEE MTT-S International Microwave and Optoelectronics Conference (IMOC) (pp. 388-392). IEEE. https://doi.org/10.1109/IMOC.2009.5427560

\section{General rights}

Copyright and moral rights for the publications made accessible in the public portal are retained by the authors and/or other copyright owners and it is a condition of accessing publications that users recognise and abide by the legal requirements associated with these rights.

- Users may download and print one copy of any publication from the public portal for the purpose of private study or research.

- You may not further distribute the material or use it for any profit-making activity or commercial gain

- You may freely distribute the URL identifying the publication in the public portal 


\title{
Submillimeter Wave Antenna With Slow Wave Feed Line
}

\author{
Vitaliy Zhurbenko ${ }^{1}$, Viktor Krozer ${ }^{1}$, Mikko Kotiranta ${ }^{1}$, Tonny Rubæk ${ }^{1}$, \\ Alain Durand ${ }^{2}$ and Rodolphe Marchesin². \\ ${ }^{1}$ Technical University of Denmark, \\ Kgs.Lyngby, Denmark. \\ 2 THALES Electron Devices, \\ Velizy, France. \\ vz@elektro.dtu.dk
}

\begin{abstract}
Submillimeter wave radiation, which is also referred to as terahertz radiation, has not been extensively explored until recently due to a lack of reliable components and devices in this frequency range. Current advances in technology have made it possible to explore this portion of the electromagnetic spectrum, and to create innovative imaging and sensing techniques that hold enormous potential in biomedical, metrological and security applications. Considering that realization of submillimeter wave components and antennas is still heavily constrained by problems arising from technological limitations and the necessity of having extremely miniaturized circuit elements, the design process remains quite challenging. In this paper, a design of a submillimeter wave antenna fed by a slow wave structure is described. The antenna is useful in high-power $\mathrm{THz}$ applications because of its ability to directly radiate energy from a vane-type interaction structure of a vacuum electron device. The parameters of the antenna are optimized while taking the technological constraints into account.
\end{abstract}

Keywords - corrugated antennas; corrugated surfaces; endfire antennas; slow wave structures; submillimeter wave antennas; surface waves.

\section{INTRODUCTION}

Antennas are key components in most submillimeter wave devices and systems. They are used everywhere where a transformation between a guided wave and a free-space wave (or vice versa) is required. In the considered frequency band, slow wave structures are often used as delay lines, filter elements, guiding wave structures and interaction structures in vacuum electron devices. Thus, by having an antenna which can be fed directly by a slow wave structure, one would avoid the use of additional transition elements allowing for better performance and more flexible design process. This type of feeding makes the antenna eminently suitable for high power, short wavelength quasi-optical launcher systems in vacuum electron devices. Such systems effectively separate the electron beam from the electromagnetic waves avoiding the implementation of highly overmoded waveguides [1]-[3]. In this paper, possibilities to decouple a surface wave from a slow wave structure in an efficient way are discussed. An extension of the low directivity corrugated surface wave antenna [4] to a highly directive antenna is described. The parametric analysis of the antenna is performed in order to optimize its radiation characteristics.

\section{FEED LINE}

The surface electromagnetic wave is guided by a copper vane-type slow wave structure shown in Figure 1. The antenna is fed by this slow wave structure. This structure is optimized for electron tube operation and has a groove for electron beam propagation. The electromagnetic wave is localized near the vane, as it is shown in Figure 1.

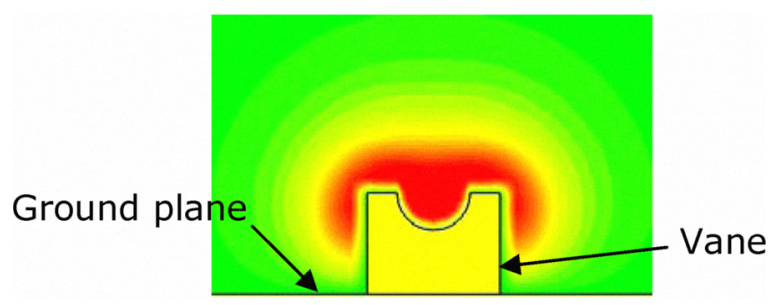

Figure 1 Axial component of the electric field.

The height of the vane can be adjusted to change the dispersion characteristic of the slow wave structure. The dimensions of the structure are optimized for operation in the terahertz range, and can be found in [5], [6].

\section{ANTENNA CONFIGURATION}

\section{A. Broadband Matching of the Antenna}

The surface electromagnetic wave can be decoupled from the open guiding structure by introducing a discontinuity into it. The discontinuity forces the surface wave to radiate into free space. In the following radiation scheme, the discontinuity is formed simply by a transition between the slow wave structure and a ground plane, as depicted in Figure 2 (a). The decoupling of the surface wave can be observed in Figure 2 (b). 


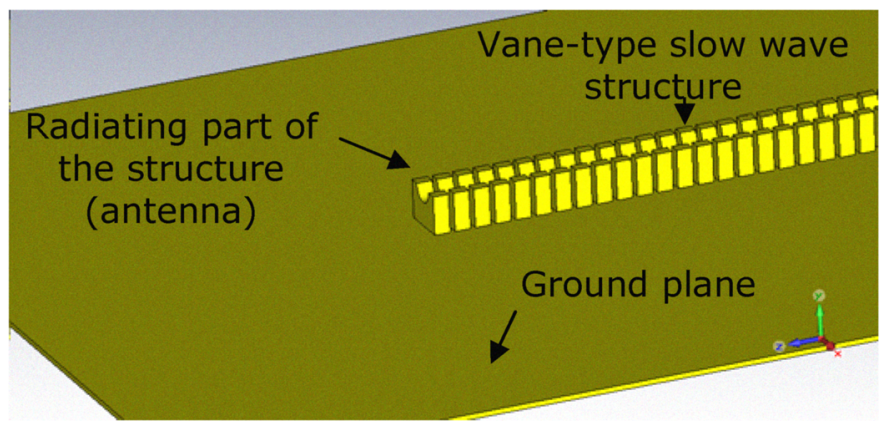

(a)

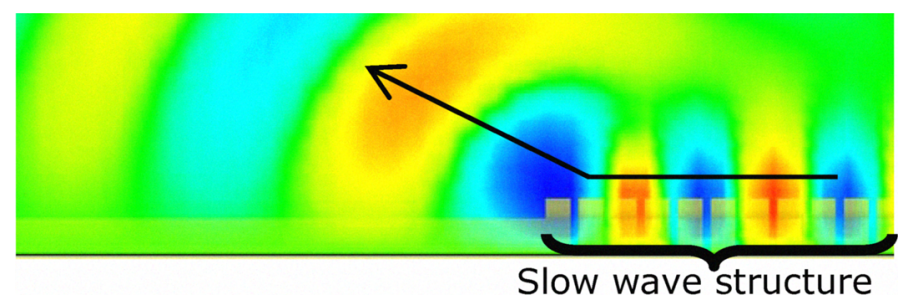

(b)

Figure 2 Surface wave antenna. (a) geometry, (b) decoupling of the surface wave (axial component of the electric field).

The advantages of such an antenna are small dimensions and an easy design procedure. The fabrication of it is simple, and the same technological process is used as in the fabrication of the slow wave structure. However, the performance of such a simple antenna is poor. The abrupt transition between the slow wave structure and the ground plane results in poor matching of the structure with free space. This means that a significant amount of electromagnetic energy is reflected back instead of being radiated into free space. For example, the return loss of a similar corrugated metal antenna measured in [4] rises up to $6 \mathrm{~dB}$. In addition, the small dimensions of the antenna result in low directivity. All these factors unavoidably affect the efficiency of the overall system.

In order to overcome these drawbacks, tapering and broadening of the radiating part of the structure can be implemented.

There are infinitely many ways to choose the taper profile. By changing the type of a continuous taper, one can obtain different passband characteristics. Several taper profiles may be considered:

- linear;

- exponential;

- triangular;

- Klopfenstein taper.

For a given taper length (greater than a critical value), the Klopfenstein has been shown to be optimum in the sense that the reflection coefficient is minimum over the passband [7]. Alternatively, for a maximum reflection coefficient specification in the passband, the Klopfenstein taper yields the shortest matching section. However, it should be noted that the response of this taper has equal level of ripples in its passband. Because of the complexity of the relation between the physical dimensions and the equivalent characteristic impedance of the considered guiding structure, the generation of an optimal tapering configuration is not a trivial task. A linear tapering of physical dimensions is implemented in this design for simplicity. This tapering technique provides a level of reflection loss acceptable in most practical cases, as it will be shown later.

There are several possibilities for the taper realization:

- height tapering;

- width tapering;

- gap tapering.

In the height tapering, the height of the vanes decreases from their nominal size to zero, as illustrated in Figure 3.

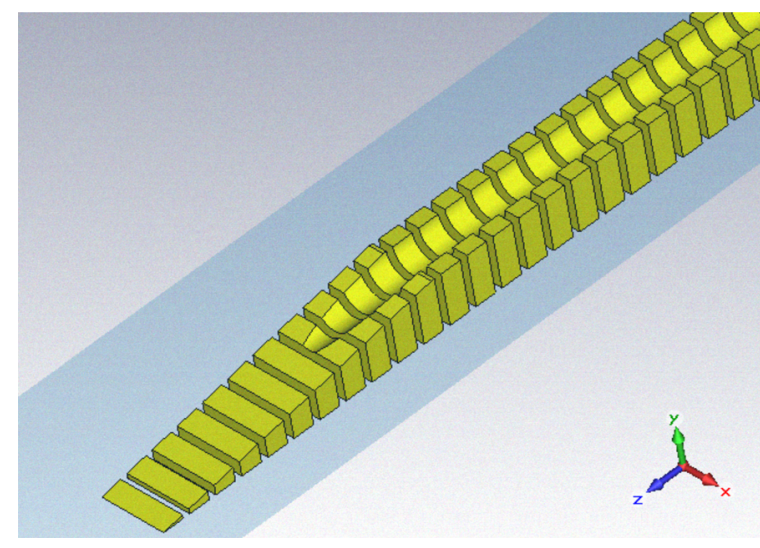

Figure 3 Height tapering.

In the width tapering, the height of all vanes is equal, which is more convenient for some lithographic microtechnologies. The width of the vanes changes from its normal value to zero, as shown in Figure 4.

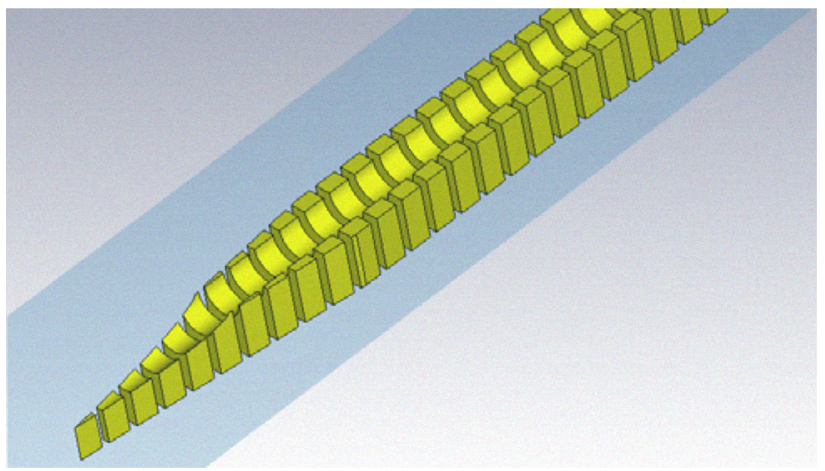

Figure 4 Width tapering 
The gap tapering is related to the variation of the distance between the vanes.

The height taper improves matching characteristics considerably over the operating frequency band of the antenna, as one can see from the data presented in Figure 5. The reflection coefficient at $900 \mathrm{GHz}$ has improved from $3 \mathrm{~dB}$ (for structure in Figure 2) to better than $15 \mathrm{~dB}$ by implementing a tapering technique.

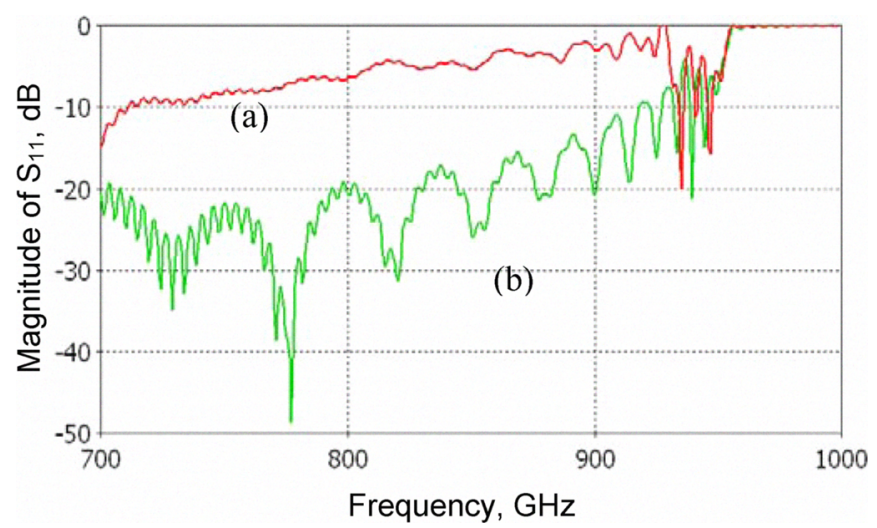

Figure 5 Matching of the antennas (a) simple configuration in Figure 2, (b) tapered configuration in Figure 3.

It should be noted that the upper stopband cut-off frequency is related to the dispersion characteristic of the slow wave structure itself.

Because tapering is a nonresonant approach, it provides matching in a wide frequency range.

\section{B. Parametric Analysis of the Antenna}

The directivity of the untapered antenna (refer to Figure 2) is slightly over $10 \mathrm{dBi}$. The $3 \mathrm{D}$ radiation patterns of this antenna at $800 \mathrm{GHz}$ and $900 \mathrm{GHz}$ are presented in Figure 6. As one can see, the beam of the antenna is tilted through a certain angle away from the direction of the slow wave structure. This helps to separate the electron beam and electromagnetic wave in vacuum electron devices.

The directivity can be further improved by making the radiating part of the structure broader, as it is shown in Figure 7. The implemented broadening narrows the width of the main lobe, as will be shown below. Besides, it has negligible impact on the matching characteristic of the antenna.

The dependence of the main lobe magnitude on the width $w$ of the antenna at $800 \mathrm{GHz}$ and $900 \mathrm{GHz}$ is shown in Figure 8 (a). The main lobe magnitude increases considerably as $w / t w$ is increased from the initial value of 1 and reaches maximum somewhere around $5 \ldots 7$ depending on the frequency of operation. The broadening has almost no effect on the side lobe level, as one can deduce from the data presented in Figure 8 (b). The side lobe level remains constant with a small variation of about $3 \mathrm{~dB}$ in the investigated range of $w$.
The influence of the length $l$ of the antenna on its radiation characteristics is shown in Figure 9. The maximum directivity is obtained for $l$ in the range $(15 \ldots 25) p$ (Figure 9 (a)). The side lobe level rises up to $-5 \mathrm{~dB}$ for large length antennas (Figure 9 (b)).
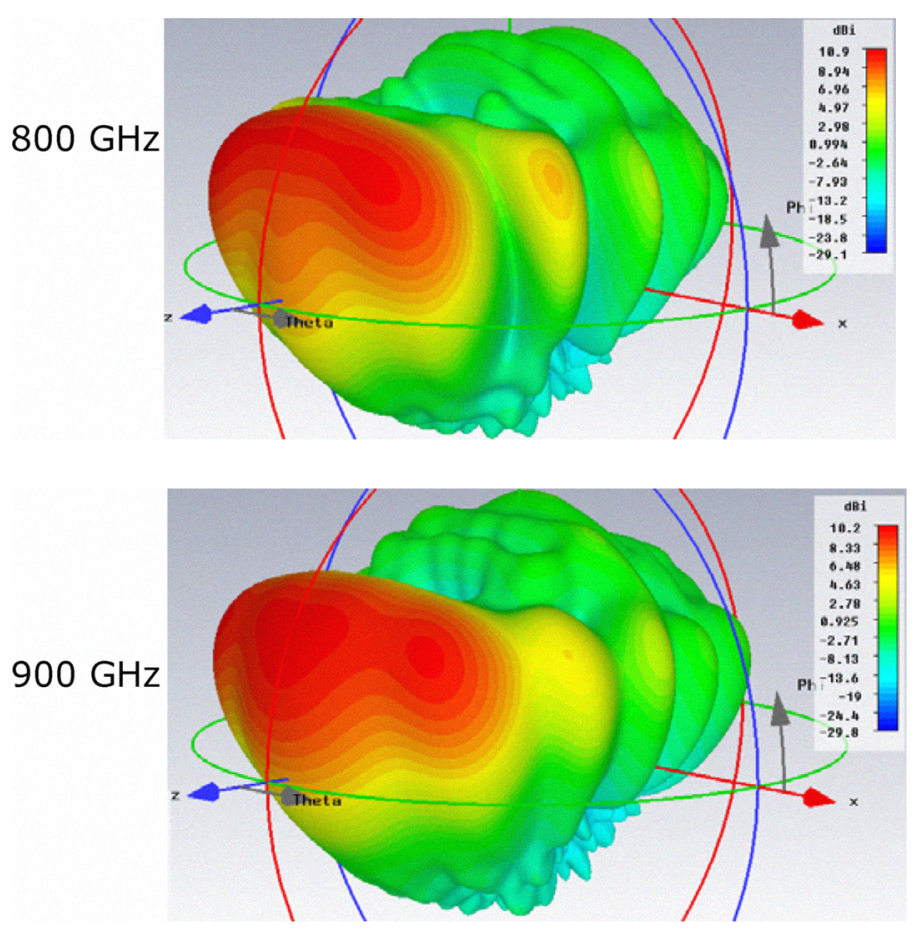

Figure 6 3D radiation pattern of the antenna in Figure 2. (a) $800 \mathrm{GHz}$; (b) $900 \mathrm{GHz}$.

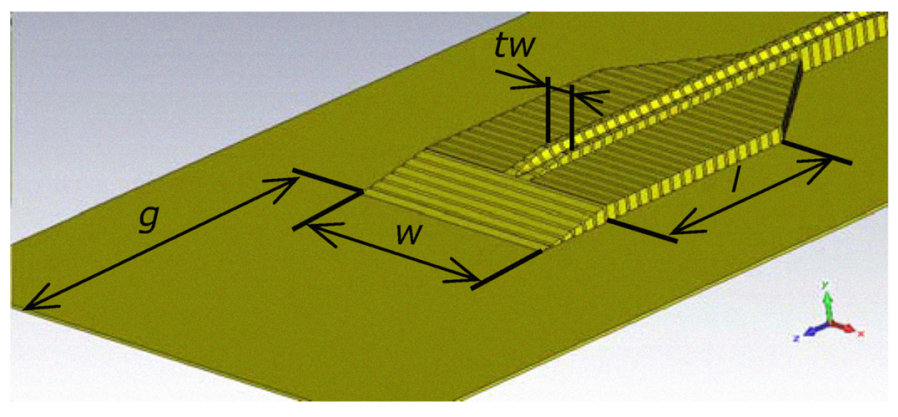

Figure 7 Radiating part of the slow wave structure (antenna). The transition between the slow wave structure and the antenna consists of 9 corrugations with a period $p$, while the one between the antenna and the ground plane consists of 10 corrugations with a period $p ; w=7 \cdot t w ; l=16 \cdot p$;

$g=25 \cdot p$. The height of the extended vanes is equal to distance from the ground plane to the groove bottom (refer to Figure 1).

The ground plane with a finite length broadens the beamwidth of the antenna. As the length of the ground plane $g$ (refer to Figure 7) increases, the beam-width decreases significantly. Consequently, the directivity of the antenna can be easily improved by extending the length of the ground plane, as clearly seen from the data in Figure 10. 


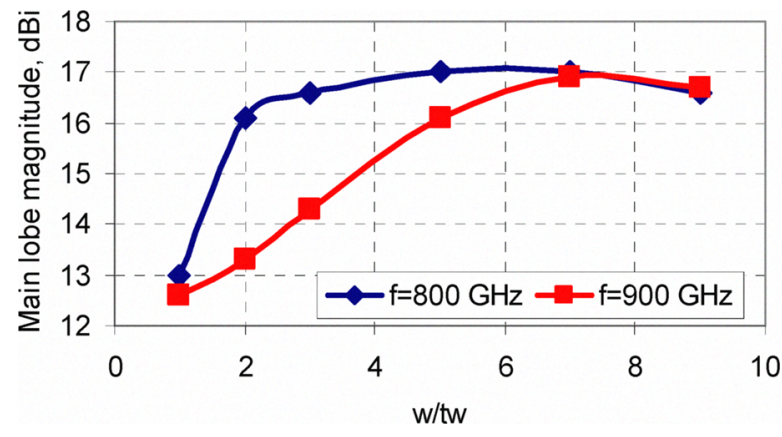

(a)

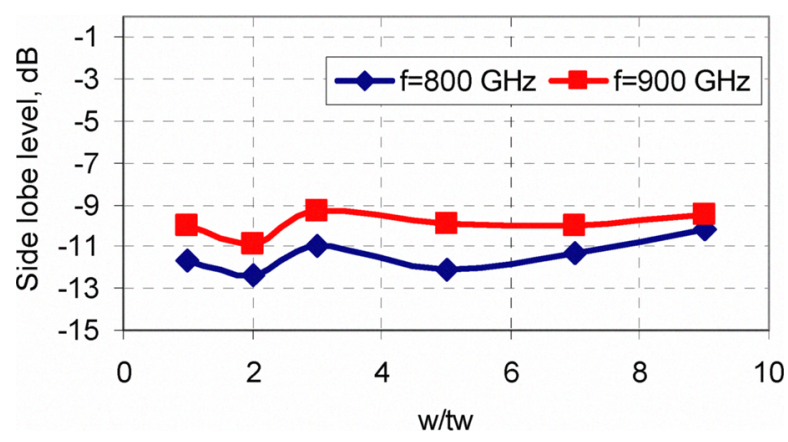

(b)

Figure 8 Radiation characteristics of the antenna versus width $w$ of it

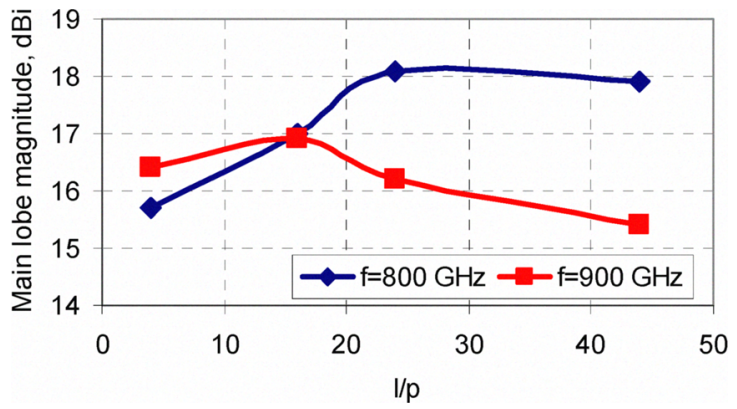

(a)

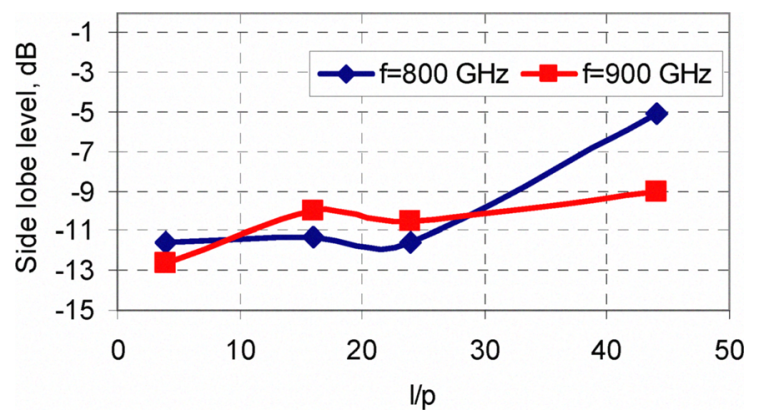

(b)

Figure 9 Radiation characteristics of the antenna versus length $l$ of it.

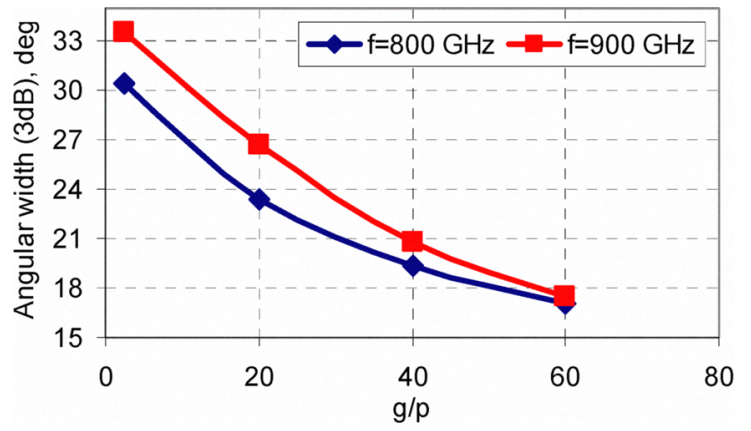

(a)

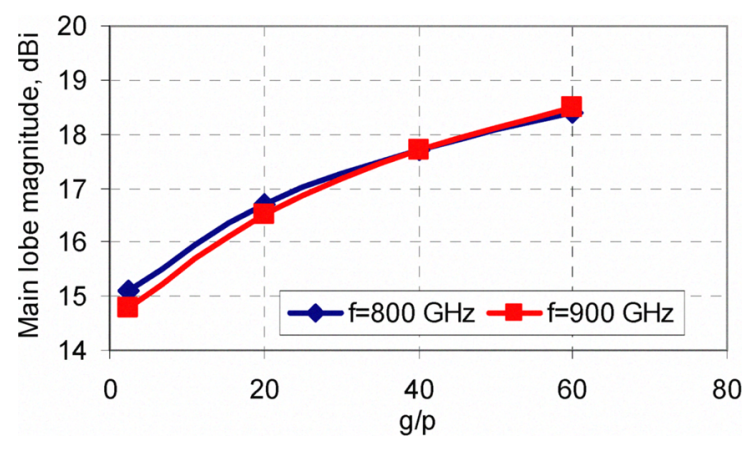

(b)

Figure 10 Radiation characteristics of the antenna versus the length of the ground plane $g$.

As expected, the direction of the main lobe shows some dependence on the length of the ground plane, as can be seen in Figure 11. However, it is difficult to reliably estimate this dependence since the angular width of the main lobe (refer to Figure 10 (a)) is higher than the angle between the direction of the guiding structure and the main lobe direction.

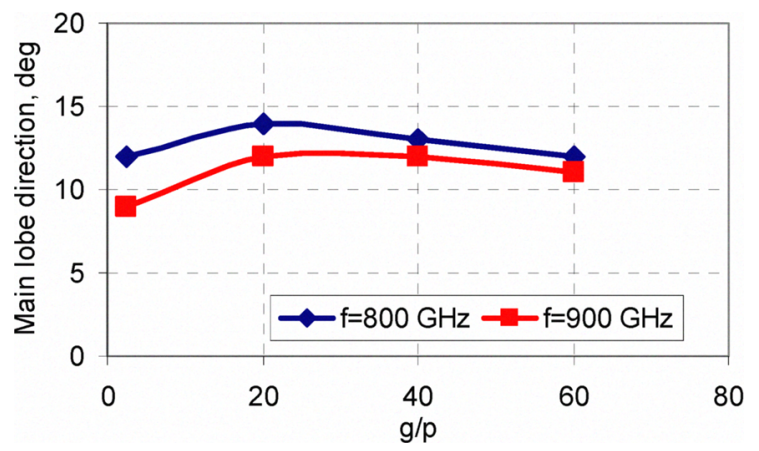

Figure 11 Main lobe direction of the antenna versus the length of the ground plane $g$.

The 3D radiation patterns of the optimized antenna (refer to Figure 7) at $800 \mathrm{GHz}$ and $900 \mathrm{GHz}$ are shown in Figure 12. 

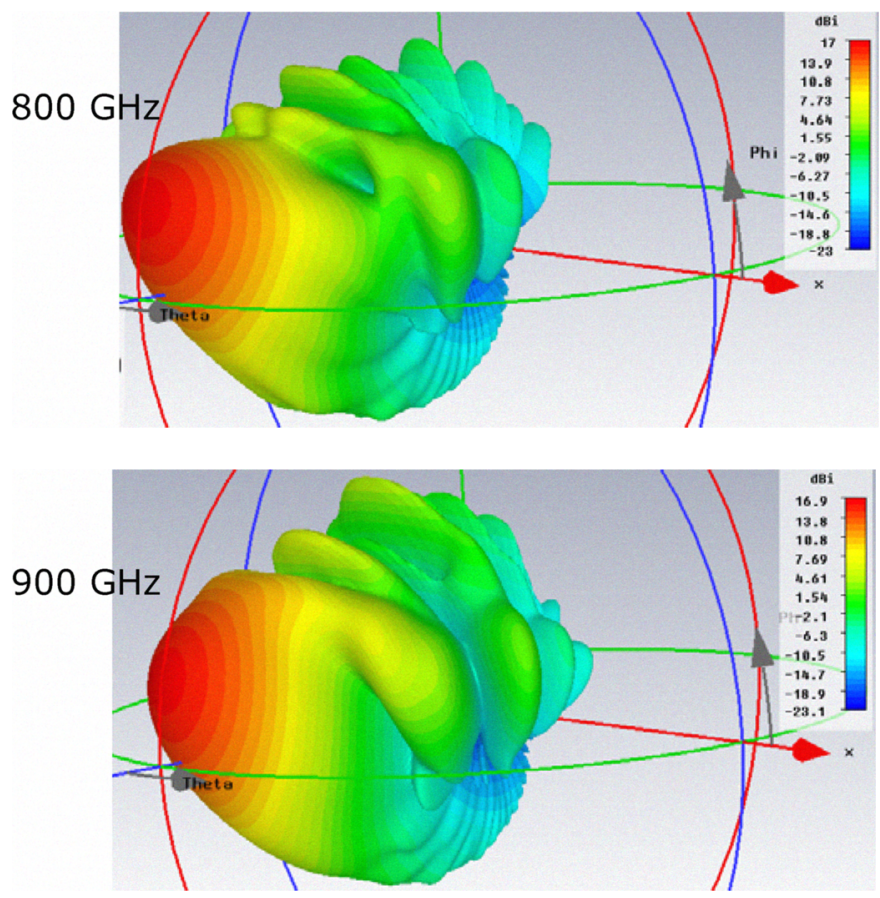

Figure 12 3D radiation pattern of the antenna in Figure 7. (a) $800 \mathrm{GHz}$ (b) $900 \mathrm{GHz}$.

The cross section of the radiation pattern through the main beam is shown in Figure 13. The directivity of the antenna is improved to about $17 \mathrm{dBi}$ by broadening the radiating part.

\section{CONCLUSIONS}

Open slow wave structures are often chosen in high power electronics in favor of traditional guiding structures, due to a better ability to prevent electrical breakdown. It is shown that the vane-type slow wave structure can be modified in such a way that it can be used for directive radiation of electromagnetic energy. The implementation of the tapering and broadening of the radiating part of the structure improves the matching and directivity of the antenna. The width and length of the antenna can be optimized for the maximum gain. The size of the ground plane has also a considerable impact on the beam-width and directivity and should be chosen as large as practically possible. The optimized antenna shows a small variation of the main lobe magnitude in the considered frequency range, maintaining the same pointing angle.

The directivity of the optimized radiating element is such that it can be used either as an antenna on its own, or as a part of a reflector antenna. The proposed antenna has a good potential for successful implementation in submillimeter wave devices and systems and also suitable for high power applications.
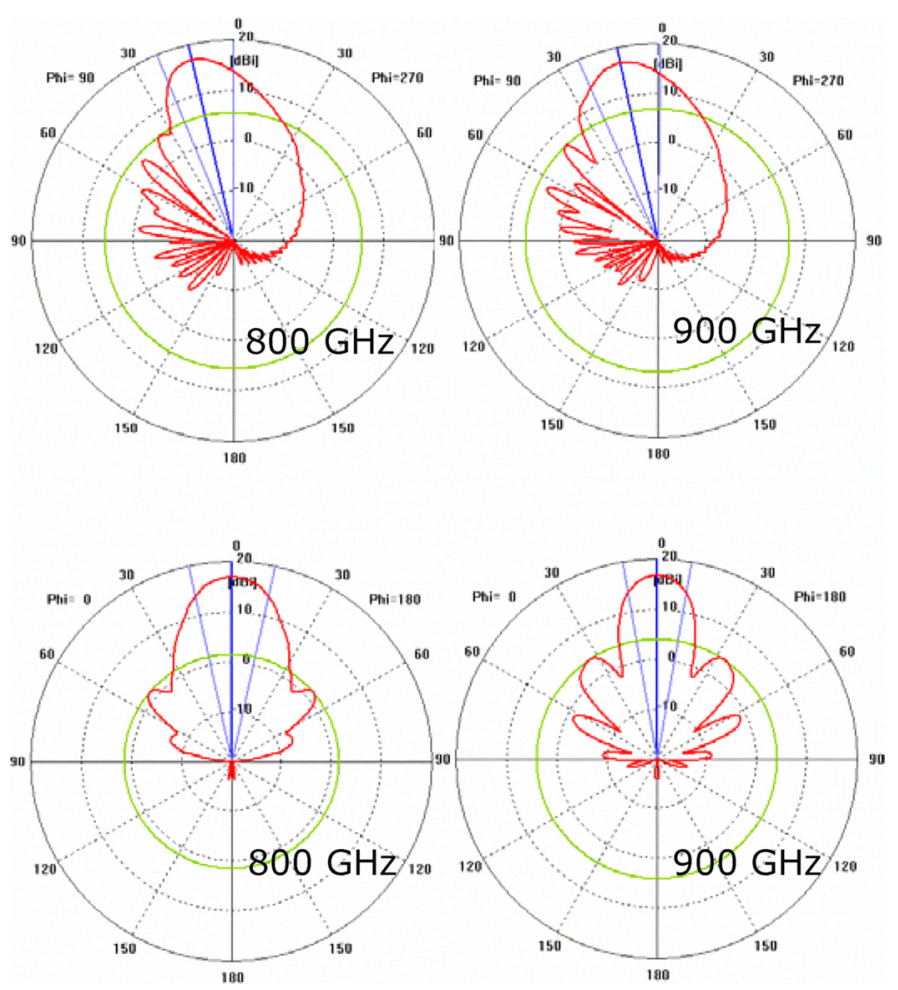

Figure 13 Cross section of the 3D radiation pattern in Figure 12.

\section{ACKNOWLEDGMENT}

This work has been supported by the FP-7 European Project n.224356 "OPTHER - Optically Driven THz Amplifiers".

\section{REFERENCES}

[1] H. O. Prinz, A. Arnold, G. Dammertz, and M. Thumm, "Analysis of a $\mathrm{TE}_{22,6}$ 118-GHz Quasi-Optical Mode Converter," IEEE Transactions On Microwave Theory And Techniques, vol. 55, No. 8, pp. 1697-1703, August 2007.

[2] M. P. Perkins, and R. J. Vernon, "Mirror Design for Use in Gyrotron Quasi-Optical Mode Converters," IEEE Transactions On Plasma Science, vol. 35, No. 6, pp. 1747-1757, December 2007.

[3] J. Benford, J. A. Swegle, and E. Schamiloglu, High Power Microwaves. $2^{\text {nd }}$ edition. Taylor \& Francis, 2007.

[4] V. Fusco, D. Romanek, and B. Nair, "V-Band Corrugated Metalantenna For Giga-Bit Wireless Applications," Microwave And Optical Technology Letters, vol. 49, No. 12, pp. 2953-2956, December 2007.

[5] P. Garcin, D. Grauleau, R. Gerber, and L. Teyssier, „New technologies used for the $1 \mathrm{THz}$ backward-wave oscillator," International Electron Devices Meeting, IEDM '88., Technical Digest., pp. 850-853,1988.

[6] Ph. Guidee, L. Teyssier, "A 850-1000 GHz backward-wave oscillator for advanced applications," Proceedings of the Instrumentation for Submillimeter Spectroscopy Meeting, p. 93-98, 1986.

[7] D.M.Pozar, Microwave Engineering. Wiley, 1998. 